NBER WORKING PAPER SERIES

\title{
COMMODITY CONNECTEDNESS
}

Francis X. Diebold

Laura Liu

Kamil Yilmaz

Working Paper 23685

http://www.nber.org/papers/w23685

\author{
NATIONAL BUREAU OF ECONOMIC RESEARCH \\ 1050 Massachusetts Avenue \\ Cambridge, MA 02138 \\ August 2017
}

For helpful comments we thank an anonymous referee, as well as Gary Gorton, Alain Kabundi, Danilo Leiva, Fabrizio Perri, and Xiao Qiao. The usual disclaimer applies. The views expressed herein are those of the authors and do not necessarily reflect the views of the National Bureau of Economic Research.

NBER working papers are circulated for discussion and comment purposes. They have not been peer-reviewed or been subject to the review by the NBER Board of Directors that accompanies official NBER publications.

(C) 2017 by Francis X. Diebold, Laura Liu, and Kamil Yilmaz. All rights reserved. Short sections of text, not to exceed two paragraphs, may be quoted without explicit permission provided that full credit, including $\left({ }^{\circ}\right.$ notice, is given to the source. 
Commodity Connectedness

Francis X. Diebold, Laura Liu, and Kamil Yilmaz

NBER Working Paper No. 23685

August 2017

JEL No. G1

\section{$\underline{\text { ABSTRACT }}$}

We use variance decompositions from high-dimensional vector autoregressions to characterize connectedness in 19 key commodity return volatilities, 2011-2016. We study both static (fullsample) and dynamic (rolling-sample) connectedness. We summarize and visualize the results using tools from network analysis. The results reveal clear clustering of commodities into groups that match traditional industry groupings, but with some notable differences. The energy sector is most important in terms of sending shocks to others, and energy, industrial metals, and precious metals are themselves tightly connected.

Francis X. Diebold

Department of Economics

University of Pennsylvania

3718 Locust Walk

Philadelphia, PA 19104-6297

and NBER

fdiebold@sas.upenn.edu

Laura Liu

Department of Economics

University of Pennsylvania

3718 Locust Walk

Philadelphia, PA 19104

yuliu4@sas.upenn.edu
Kamil Yilmaz

Department of Economics

Koc University

Rumelifeneri Yolu, Sariyer

Istanbul 34450

kyilmaz@ku.edu.tr 


\section{Contents}

1 Introduction 1

2 Commodities Data and Volatility 2

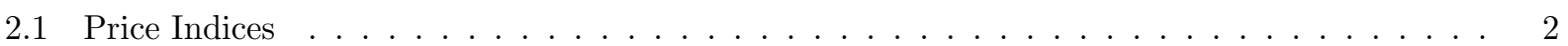

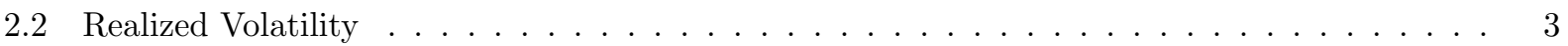

3 Benchmark Results I: Static (Full-Sample) Connectedness 5

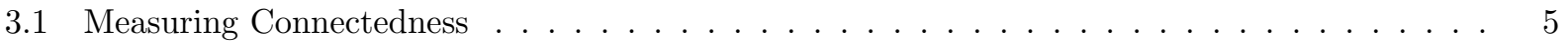

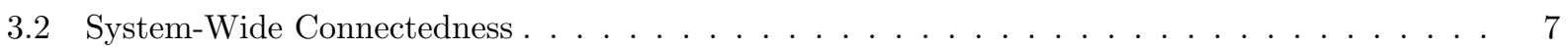

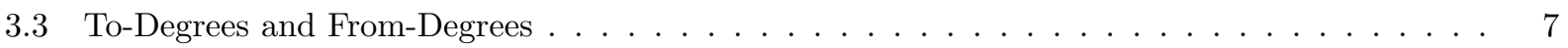

3.4 The Network Graph . . . . . . . . . . . . . . . . . . . . . . . 8

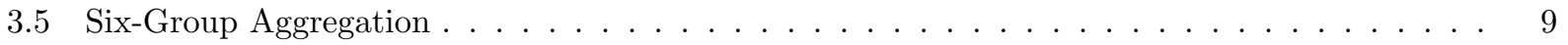

4 Benchmark Results II: Dynamic (Rolling-Sample) Connectedness 11

4.1 On the Economics of Commodity Connectedness Dynamics . . . . . . . . . . . . . . 11

4.2 System-Wide Connectedness . . . . . . . . . . . . . . . . . . . . . . 13

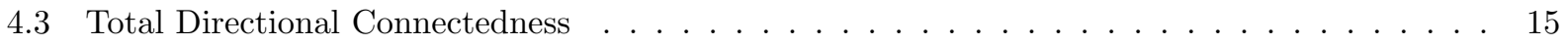

5 Conclusion $r$

$\begin{array}{lr}\text { Appendices } & 19\end{array}$

$\begin{array}{lr}\text { A Verification of Key Properties of Realized Volatility } & 19\end{array}$

B Different Horizons (Various $h$, Fixed $p=3$ ) 20

C Different Dynamics (Fixed $h=10$, Various $p$ ) 20 


\section{Introduction}

Commodities and commodity markets play a central role in the global economy. ${ }^{1}$ Hence commodity market developments are widely chronicled and followed. ${ }^{2}$ Commodities are a key input to all countries' production, and a key output of many emerging economies, so fluctuations in commodity prices may contribute strongly to common business cycle fluctuations in emerging economies and beyond, as emphasized by Fernández et al. (2015). Commodities have also emerged as important financial asset classes (e.g., energy, agriculture, metals), with properties different from those of "traditional" asset classes like stocks, bonds, and foreign exchange, as emphasized by Kat and Oomen (2007a) and Kat and Oomen (2007b).

Understanding connectedness, which is central to risk measurement and management, seems particularly important in the commodities context, particularly for emerging economies relying heavily on commodities production. Relevant aspects include connectedness across firms, markets, and countries, both nominal/financial and real. In particular, we have in mind things like connectedness of commodity company stocks (both within and across countries), connectedness of commodity prices, and links between commodity price connectedness and country real output connectedness.

Moreover, connectedness measurement in real time is of special relevance for policy. Successful real-time policy (and all policy is real-time) demands real-time monitoring, often exploiting high-frequency data. ${ }^{3}$ As we shall later describe in detail, the daily commodity volatilities that we study in this paper are in precisely that tradition, built from key parts of trade-by-trade intra-day price paths.

Several approaches to connectedness measurement have been considered recently. ${ }^{4}$ Billio et al. (2012) use pairwise Granger causality. Bonaldi et al. (2013) work with vector autoregressions (VAR's), which allow for full multivariate dynamic cross-variable interaction and hence richer connectedness assessment, focusing on connectedness due to cross-lag interactions as opposed to innovation correlations. Diebold and Yilmaz (2009), Diebold and Yilmaz (2012), and Diebold and Yilmaz (2014) also use VAR's, but they use variance decompositions, which account for innovation correlations in addition to dynamic cross-variable interactions. ${ }^{5}$ Demirer et al. (2016) extend the Diebold-Yilmaz framework to high-dimensional

\footnotetext{
${ }^{1}$ For a broad overview from an empirical perspective, see Chevallier and Ielpo (2013).

${ }^{2}$ See, for example, the World Bank Commodity Market Outlook, http://www.worldbank.org/en/ research/commodity-markets.

${ }^{3}$ See, for example, John Taylor's inaugural Feldstein Lecture at the National Bureau of Economic Research, (http://www.nber.org/feldstein_lecture/feldsteinlecture_2009.html).

${ }^{4}$ For an interpretive survey see Kara et al. (2015).

${ }^{5}$ The Diebold and Yilmaz (2014) framework extends earlier variance-decomposition work by Diebold and
} 
environments, which are increasingly relevant, by incorporating LASSO estimation.

In this paper, we characterize global commodity market connectedness using the Demirer et al. (2016) framework. This is of interest in a variety of contexts. One such key context is private-sector investment management strategies, whose portfolio concentration risk is directly related to connectedness. Another is public-sector monitoring and policy formulation, because connectedness tends to increase during commodity-market crises, which may then spill over into the broader macroeconomy.

We proceed as follows. In section 2 we discuss our commodity price indices, our construction and verification of realized return volatility, and our framework for measuring commodity volatility connectedness. In section 3 we provide benchmark results for static connectedness, and in section 4 we provide results for dynamic connectedness. We conclude in section 5, and we explore variations and extensions in several appendices.

\section{Commodities Data and Volatility}

In this section we describe our commodities data - prices, returns, and range-based return volatilities - and their properties.

\section{$2.1 \quad$ Price Indices}

We study nineteen sub-indices of the Bloomberg Commodity Price Index: four energy commodities (crude oil, heating oil, natural gas, unleaded gasoline), two precious metals (gold, silver), four industrial metals (aluminum, copper, nickel, zinc), two livestock commodities (live cattle, lean hogs), four grains (corn, soybeans, soybean oil, wheat), and three so-called "softs" (coffee, cotton, sugar). It is important to note that the category labeling is not ours; rather, it is standard among industry participants, which will subsequently be of interest later when interpreting our empirical results. ${ }^{6}$ Details on the underlying futures contracts, and the exchanges on which they are traded, appear in Table $1 .^{7}$

The nineteen sub-indices that we study are those underlying the Bloomberg Commodity

Yilmaz, including Diebold and Yilmaz (2009) and Diebold and Yilmaz (2012), by using network visualization methods to understand the variance decompositions. Importantly, moreover, as emphasized in Diebold and Yilmaz (2014), the Diebold-Yilmaz framework allows measurement of connectedness at levels ranging from highly granular to highly aggregative, with close connections to marginal expected shortfall or S-risk (Acharya et al. (2010)) and CoVaR (Adrian and Brunnermeier (2016)).

${ }^{6}$ See Bloomberg (2016).

${ }^{7}$ Based on Bloomberg (2016), Table 2. 
Table 1: Commodity Contracts

\begin{tabular}{lllll}
\hline \hline Commodity & Designated Contract & Exchange & Units & Price Quote \\
\hline Natural Gas & Henry Hub Natural Gas & NYMEX & $10,000 \mathrm{mmbtu}$ & USD/mmbtu \\
WTI Crude Oil & Light, Sweet Crude Oil & NYMEX & $1,000 \mathrm{barrels}$ & USD/barrel \\
Unleaded Gasoline & RBOB & NYMEX & 42,000 gal & U.S. cents/gallon \\
ULS Diesel (Heating Oil) & ULS Diesel & NYMEX & 42,000 gallons & U.S. cents/gallon \\
Live Cattle & Live Cattle & CME & $40,000 \mathrm{lbs}$ & U.S. cents/pound \\
Lean Hogs & Lean Hogs & CME & $40,000 \mathrm{lbs}$ & U.S. cents/pound \\
Wheat & Soft Wheat & CBOT & $5,000 \mathrm{bushels}$ & U.S. cents/bushel \\
Corn & Corn & CBOT & $5,000 \mathrm{bushels}$ & U.S. cents/bushel \\
Soybeans & Soybeans & CBOT & $5000 \mathrm{bushels}$ & U.S. cents/bushel \\
Soybean Oil & Soybean Oil & CBOT & $60,000 \mathrm{lbs}$ & U.S. cents/pound \\
Aluminum & High Grade Primary Aluminum & LME & 25 metric tons & USD/metric ton \\
Copper & Copper & COMEX & $25,000 \mathrm{lbs}$ & U.S. cents/pound \\
Zinc & Special High Grade Zinc & LME & 25 metric tons & USD/metric ton \\
Nickel & Primary Nickel & LME & 6 metric tons & USD/metric ton \\
Gold & Gold & COMEX & 100 troy oz. & USD/troy oz. \\
Silver & Silver & COMEX & 5000 troy oz. & U.S. cents/troy oz. \\
Sugar & World Sugar No. 11 & NYBOT & $112,000 \mathrm{lbs}$ & U.S. cents/pound \\
Cotton & Cotton & NYBOT & $50,000 \mathrm{lbs}$ & U.S. cents/pound \\
Coffee & Coffee 'C' & NYBOT & $37,500 \mathrm{lbs}$ & U.S. cents/pound \\
\hline
\end{tabular}

Price Index when we obtained our data sample. ${ }^{8}$ Our data are daily, 2006/5/11 - 2016/1/25, with holidays and weekends dropped. This results in 2,443 observations per series, for a total of $2443 \times 19=46,417$ observations. We show time-series plots of log sub-indices in Figure 1.

\section{$2.2 \quad$ Realized Volatility}

We define commodity returns as change in log price, and we study daily range-based realized commodity-return volatility. That is, following Garman and Klass (1980) we construct rangebased realized volatility (variance) as:

$$
\begin{aligned}
\hat{\sigma}_{i t}^{2}= & 0.511\left(H_{i t}-L_{i t}\right)^{2}-0.019\left[\left(C_{i t}-O_{i t}\right)\left(H_{i t}+L_{i t}-2 O_{i t}\right)\right. \\
& \left.-2\left(H_{i t}-O_{i t}\right)\left(L_{i t}-O_{i t}\right)\right]-0.383\left(C_{i t}-O_{i t}\right)^{2}
\end{aligned}
$$

where $H_{i t}, L_{i t}, O_{i t}$ and $C_{i t}$ are, respectively, the logs of daily high, low, opening, and closing prices for commodity $i$ on day $t$.

Range-based realized volatility is almost as efficient as realized volatility based on ultrahigh-frequency sampling (it is based on the key pieces of the intra-day price path - open,

\footnotetext{
${ }^{8}$ Subsequently Bloomberg (2016) slightly enlarged the set of underlying sub-indices.
} 
Figure 1: Time Series Plots of Log Commodity Sub-Indices
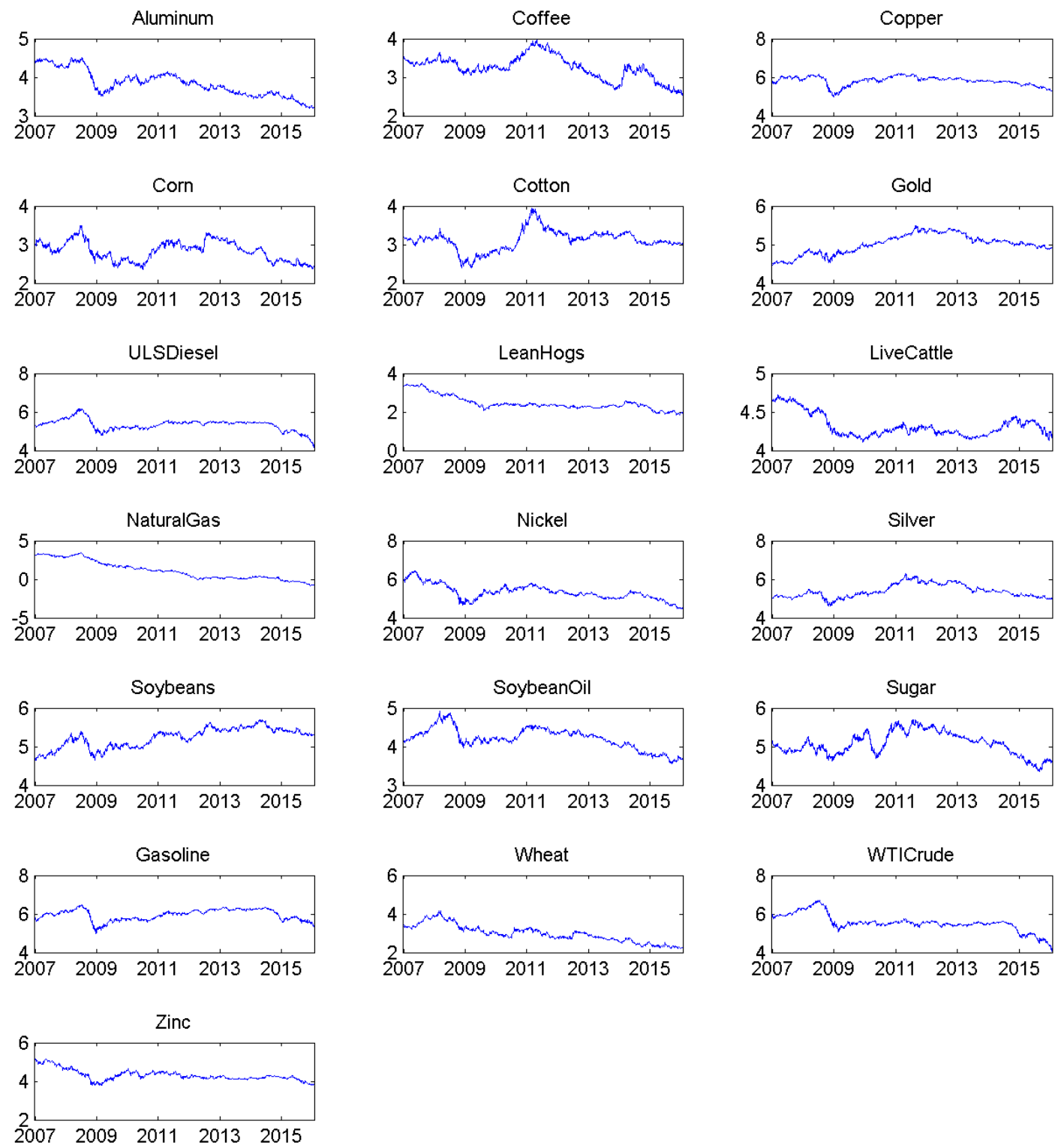
close, high, low), much less tedious to construct, robust to microstructure noise, and widely available, often for many decades. ${ }^{9}$

In Appendix A we verify the key properties of realized volatility. Results for other markets like equities (Andersen et al. (2001a)) and foreign exchange (Andersen et al. (2001b)) indicate that daily realized volatilities are (1) generally distributed asymmetrically, with a right skew, (2) approximately Gaussian after taking natural logarithms, and (3) very strongly serially correlated. Despite the fact that the economics of commodity markets are quite different from those of foreign exchange or equities, the results in Appendix A make clear that all three properties hold for commodity returns. Given property (2), from this point onward we work in logarithms. That is, even if we simply say "realized volatility" or "volatility", we mean the natural logarithm of range-based realized volatility as defined in equation (1). We show time-series plots of the log realized volatilities in Figure 2.

\section{Benchmark Results I: Static (Full-Sample) Connect- edness}

\subsection{Measuring Connectedness}

We examine commodity return volatility connectedness using the framework of Demirer et al. (2016), which builds on Diebold and Yilmaz (2014). In particular, for the benchmark results that we report in sections 3 and 4 :

1. We use a $V A R(3)$ approximating model, estimated using an adaptive elastic net with penalty parameter chosen by 10 -fold cross validation.

2. We identify the estimated $V A R$ using the generalized approach of Koop et al. (1996) and Pesaran and Shin (1998), and then we examine variance decompositions at horizon $H=10$ days.

3. We summarize the variance decomposition matrix using connectedness statistics (pairwise directional, total directional "to" and "from", and system-wide).

4. We visualize the variance decomposition matrix using network "spring graphs".

5. In Appendix B we explore different horizons (various $h$, fixed $p=3$ ), and in Appendix C we explore different approximating models (fixed $h=10$, various $p$ ).

\footnotetext{
${ }^{9}$ See Alizadeh et al. (2002).
} 
Figure 2: Time Series Plots of Log Realized Volatilities
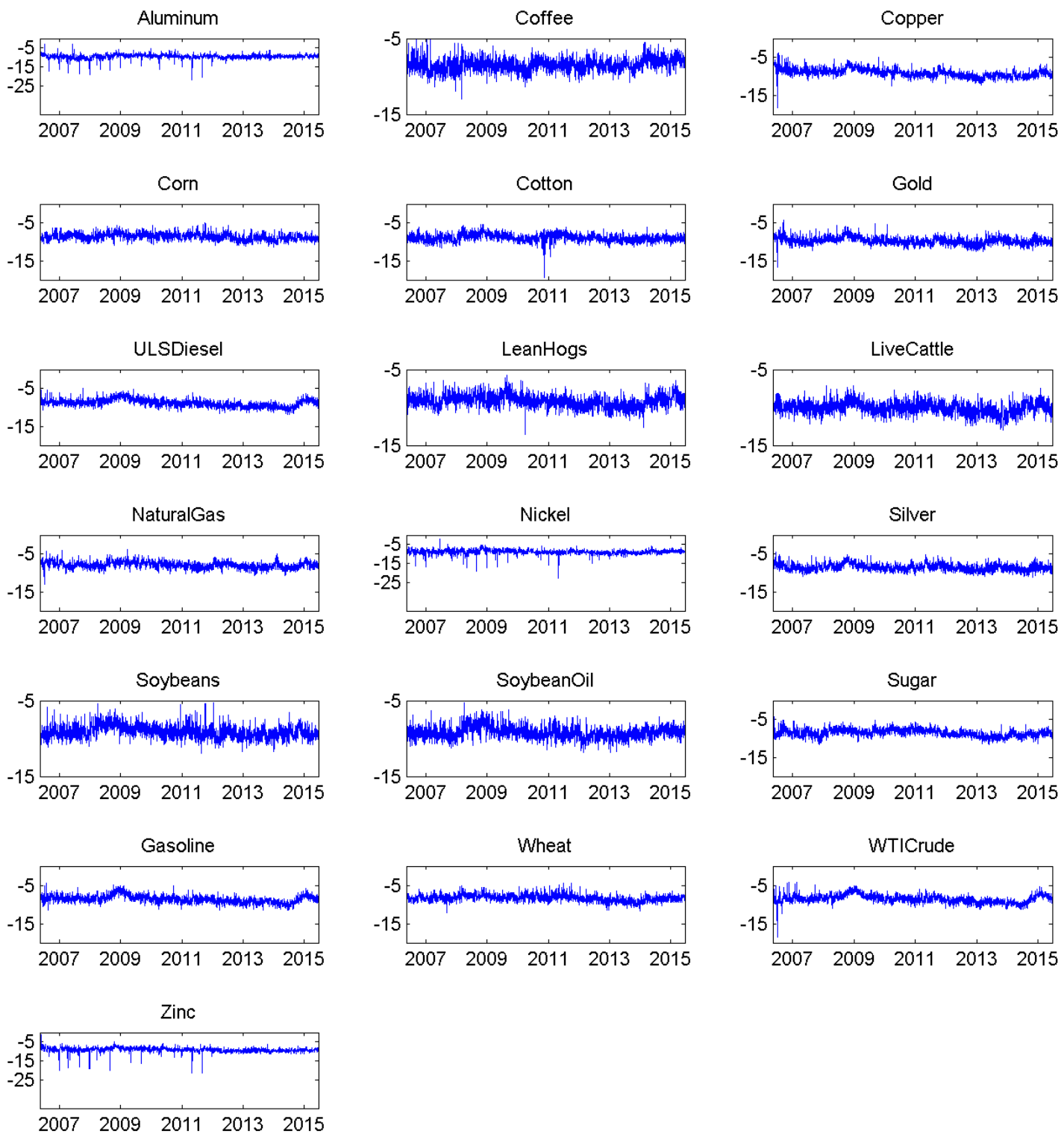
We perform static (full-sample) analyses in this section, and dynamic (rolling-sample) analyses in section 4.

Let us elaborate upon our approach to network visualization. Node shading indicates total directional connectedness "to others"; the darker the stronger. The spring graph node location layout represents a steady state in which repelling and attracting forces exactly balance, where (1) nodes repel each other, but (2) edges attract the nodes they connect according to average pairwise directional connectedness. ${ }^{10}$ Edge thickness also indicates average pairwise directional connectedness. Finally, edge arrow size indicates pairwise directional connectedness "to" and "from".

\section{$3.2 \quad$ System-Wide Connectedness}

System-wide connectedness is $40 \%$. That is, on average almost half of a commodity's future volatility uncertainty is due to "non-own" shocks. It is interesting that the $40 \%$ systemwide commodity return volatility connectedness is significantly lower than the system-wide equity return volatility connectedness found by Demirer et al. (2016) for the world's largest banks. It makes sense, however, as large parts of commodity price movements come from idiosyncratic fluctuations in national and regional macroeconomic fundamentals that drive commodity supply and demand.

\subsection{To-Degrees and From-Degrees}

It is of interest to know the individual commodity degrees, particularly to-degrees, as we are especially interested in which sectors are sending the most uncertainty to others. From largest to smallest, the to-degree ranking is ULS Diesel, WTI Crude Oil, Unleaded Gasoline, Soybeans, Gold, Zinc, Copper, Silver, Corn, Soybean Oil, Wheat, Aluminum, Nickel, Sugar, Cotton, Live Cattle, Lean Hogs, Natural Gas, and Coffee. From largest to smallest, the fromdegree ranking is ULS Diesel, WTI Crude Oil, Unleaded Gasoline, Zinc, Gold, Soybeans, Copper, Silver, Corn, Soybean Oil, Aluminum, Wheat, Nickel, Live Cattle, Cotton, Lean Hogs, Sugar, Natural Gas, and Coffee. The rank correlation is 0.9794. Bar charts appear in Figure 3, ordered by to-degrees from largest to smallest. It is interesting to note that the to-degree ordering is almost identical to the from-degree ordering.

In Figure 4, we show estimates of the the static (full-sample) "from" and "to" degree

\footnotetext{
${ }^{10}$ The steady state node locations depend on initial node locations and hence are not unique. They are, however, topologically unique up to rotation and flipping.
} 
Figure 3: Full-Sample Individual Commodity From/To Degrees
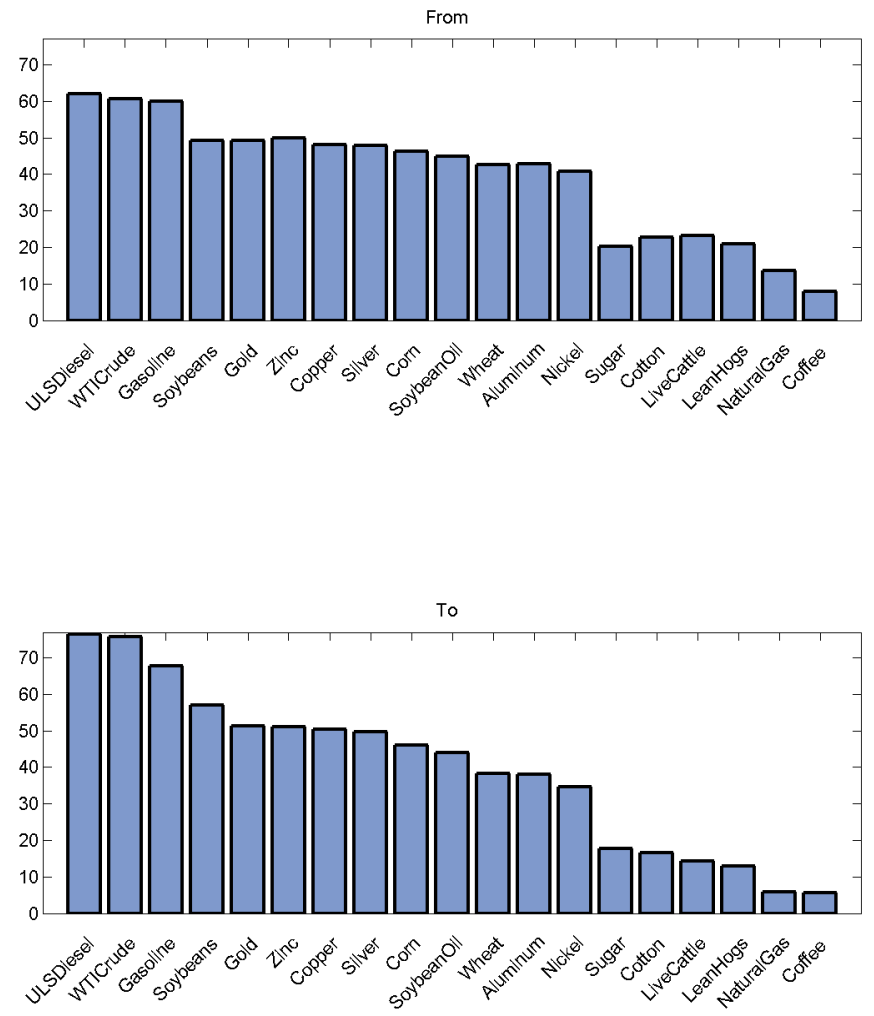

distributions, based on three-bin histograms. Their means are of course equal, and equal to system-wide connectedness (again, 40\%). Their shapes are similar but slightly different. The "to" degree distribution has a slightly thicker right tail, consistent with a few commodities sending a rather large amount of future uncertainty to others.

\subsection{The Network Graph}

In Figure 5, we show the static (full-sample) network graph. Several aspects are notable. First, there is clear clustering, associated primarily with the traditional industry groupings (energy, industrial metals, precious metals, grains, livestock, and softs), perhaps due to the nature of production processes; e.g., upstream/downstream, substitutes/complements, etc. This implies that a commodity volatility shock is likely to be transmitted to the commodity's sub-group, but not necessarily to all commodities. So we have an interesting situation: rather low system-wide connectedness, but clear group clustering and high within-group connectedness. 
Figure 4: Full-Sample From and To Degree Distributions
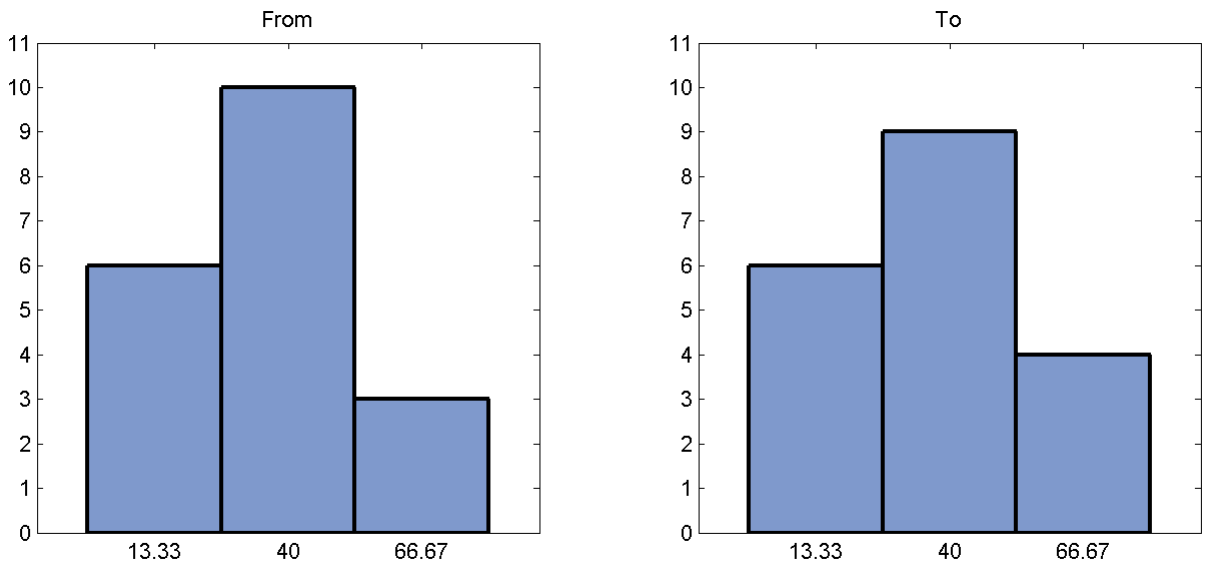

Let us elaborate on the group clustering.

1. There is clear clustering in precious metals, grains, and livestock.

2. There is clear clustering in energy and industrial metals, but in each case with a noteworthy exception. In the energy group, heating oil, crude oil, and gasoline cluster tightly, but natural gas is quite far away. In the industrial metals group, aluminum, nickel, and zinc cluster tightly, but copper is noticeably elsewhere, closer to precious metals and energy. Perhaps this "copper anomaly" is due to its role in production. Alternatively, perhaps it is not a copper anomaly, but rather an "aluminum-nickel-zinc anomaly" associated with the London Metals Exchange rules mentioned in Appendix A.

3. There is no clustering in softs (coffee, cotton, sugar). Presumably this is because softs is largely a residual category.

Taken together, (1), (2), and (3) suggest that the traditional commodity groupings are largely, but not entirely, accurate. Natural gas, in particular, is far from the other energy commodities.

\subsection{Six-Group Aggregation}

We present full numerical results in a six-group $(6 \times 6)$ "connectedness table", or "variance decomposition table" (Table 2), obtained by aggregating the original $(19 \times 19)$ connectedness table within the six traditional commodity categories (energy, industrial metals, precious 
Figure 5: Full-Sample Network Graph

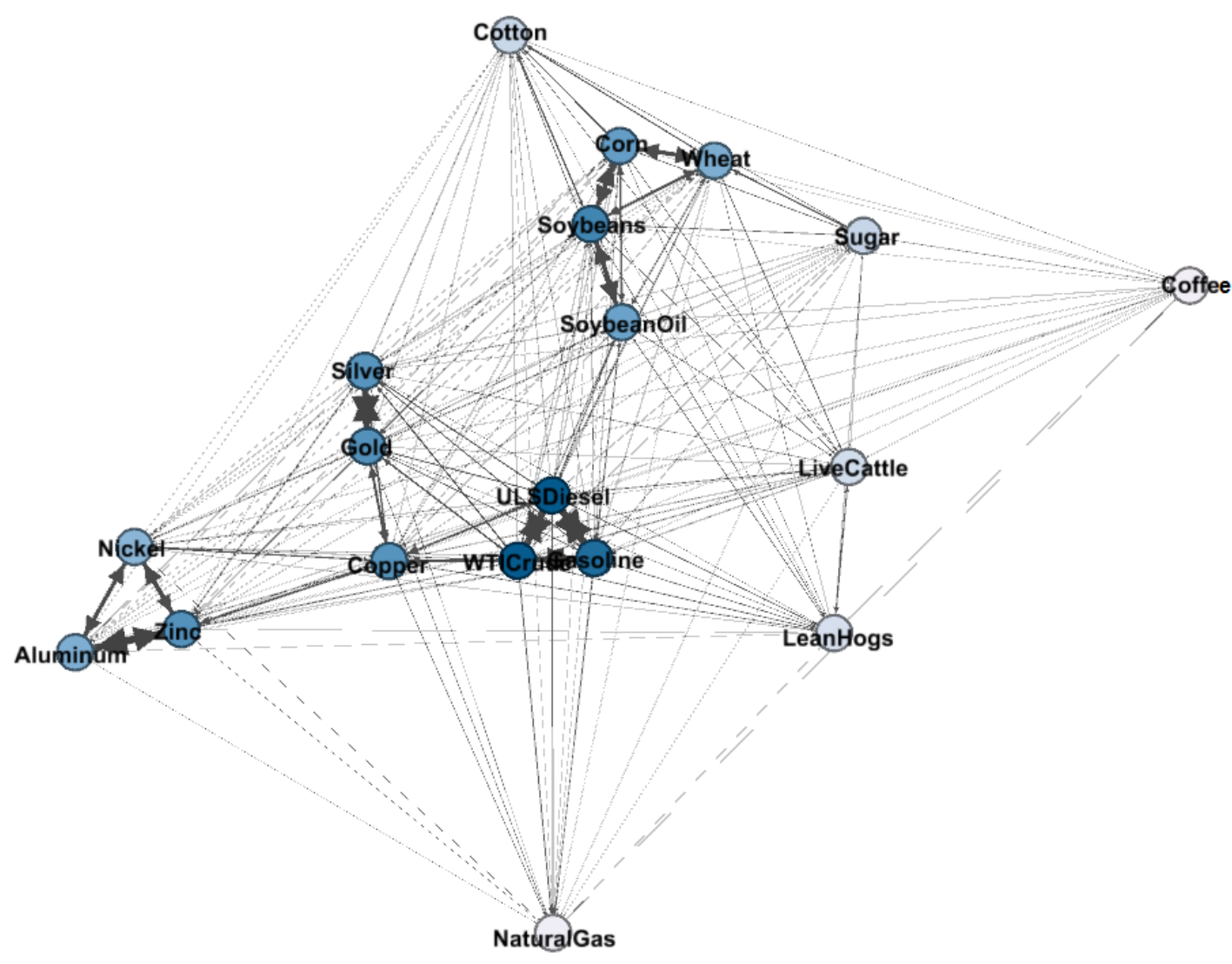

metals, grains, livestock, softs). ${ }^{11}$ The individual entries are pairwise directional connectedness, the row sums are total directional connectedness "from", the column sums are total directional connectedness "to", and the grand sum in the lower right corner is system-wide connectedness. ${ }^{12}$

We show the associated network graph for the six-group aggregation in Figure 6. There are several results. First, the energy, industrial metals, and precious metals groups themselves form a tight cluster. Second, there is a very large amount of total directional connectedness to others from energy. Third, livestock and softs are largely peripheral and net receivers, rather than transmitters, of shocks.

\footnotetext{
${ }^{11}$ In principle we could of course have shown a $(19 \times 19)$ connectedness table earlier, but its size proved unwieldy.

${ }^{12}$ All sums exclude the main diagonal, because we are interested in non-own transmissions.
} 
Table 2: Full-Sample Connectedness Table, Six-Group Aggregation

\begin{tabular}{lrrrrrr|l}
\hline \hline & Energy & Grains & Ind. Metals & Prec. Metals & Softs & Livestock & From \\
\hline Energy & $\mathrm{N} / \mathrm{A}$ & 17.11 & 21.59 & 16.49 & 6.01 & 5.43 & 66.63 \\
Grains & 23.05 & $\mathrm{~N} / \mathrm{A}$ & 7.23 & 10.57 & 18.06 & 7.02 & 65.93 \\
Ind. Metals & 30.67 & 8.35 & $\mathrm{~N} / \mathrm{A}$ & 22.88 & 2.94 & 3.05 & 67.88 \\
Prec. Metals & 20.78 & 9.38 & 20.28 & $\mathrm{~N} / \mathrm{A}$ & 3.26 & 1.11 & 54.80 \\
Softs & 8.33 & 22.88 & 4.75 & 5.67 & $\mathrm{~N} / \mathrm{A}$ & 3.63 & 45.25 \\
Livestock & 13.48 & 10.39 & 6.09 & 3.09 & 4.22 & $\mathrm{~N} / \mathrm{A}$ & 37.26 \\
\hline To & 96.30 & 68.10 & 59.94 & 58.70 & 34.48 & 20.23 & 56.29 \\
\hline
\end{tabular}

\section{Benchmark Results II: Dynamic (Rolling-Sample) Connectedness}

Here we study time series of connectedness, estimated using a rolling window with a width of 150 days. We study both total system-wide and total directional (to and from) connectedness.

\subsection{On the Economics of Commodity Connectedness Dynamics}

Thus far we have introduced our commodity price index data, constructed the corresponding returns and return volatilities, and provided a basic statistical characterization. Here we delve into more economic aspects.

Commodity prices differ in important ways from those of bonds and stocks. Unlike bonds and stocks, commodity prices are determined more by traditional supply and demand considerations. Perhaps with the exception of precious metals, which in significant part serve as alternative investment vehicles to hedge against global uncertainty, demand for commodities is closely linked to global income. In that regard, at times commodity prices can be subject to highly-correlated demand-side shocks. This was indeed the case during the global financial crisis, when prices of all major commodities dropped sharply as the near-collapse of global financial markets led to the Great Global Recession of 2009.

The emergence of China as a global economic powerhouse since the early 2000s provides another example of how commodity prices are affected by global consumption demand. From 2001 to 2011, China's industrial production quadrupled, its consumption of industrial metals increased by 330\%, and its oil consumption increased by $98 \%$ (see World Bank (July 2015)). China's phenomenal growth in commodity demand is reflected in a broad upward trend in commodities prices that lasted until 2011 and then subsided as demand from China and 
Figure 6: Full-Sample Network Graph, Six-Group Aggregation

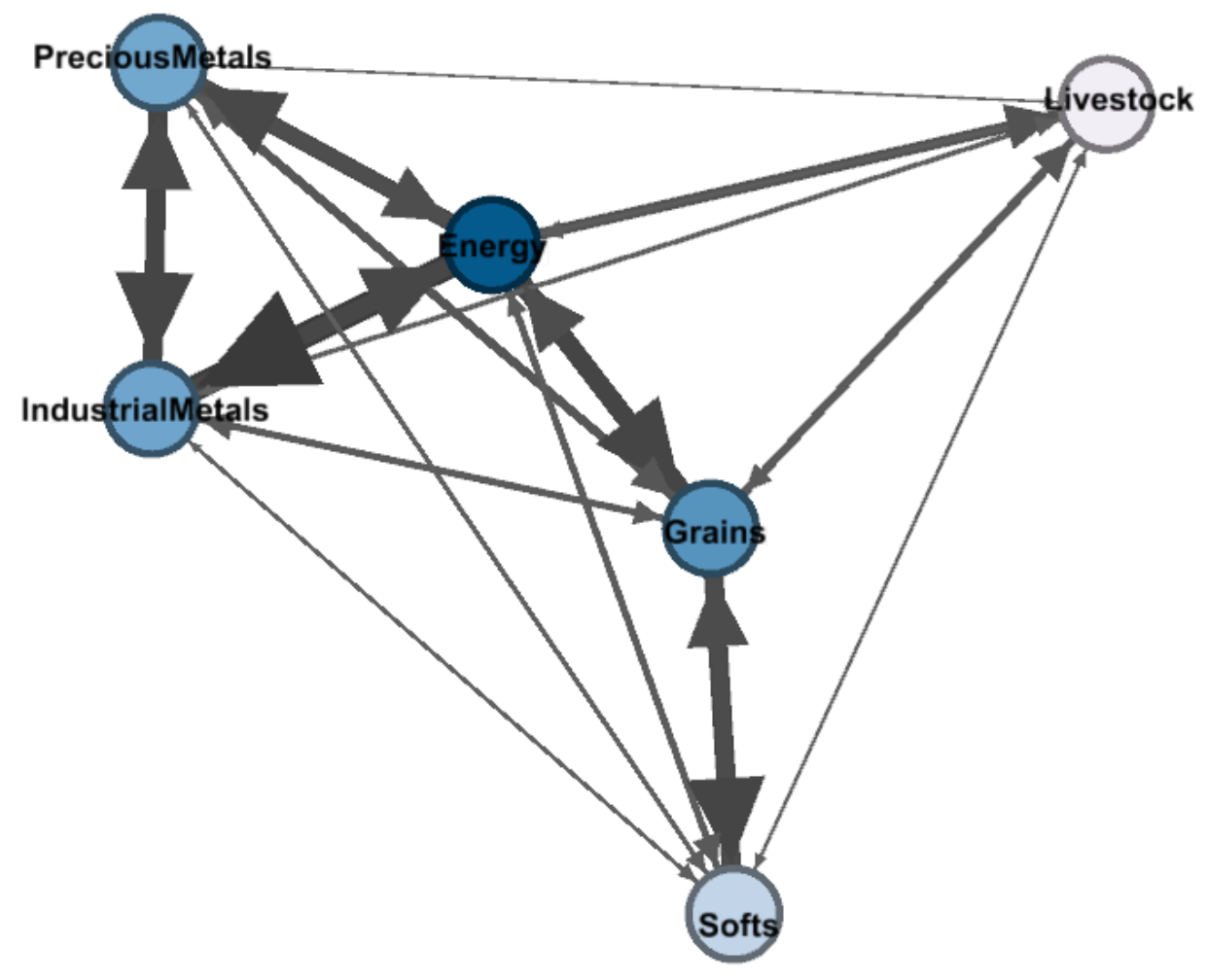

other emerging-market economies subsided (see World Bank (October 2014)).

Unlike commodity demand, which is driven at least in part by a common "global demand" factor, commodity supply is more idiosyncratic. Supplies of energy, industrial metals, precious metals, and agricultural commodities can be affected by very different factors. For example, while OPEC controls part of the global oil supply, a larger share of global oil supply as well as supplies of metals can be affected by the decisions of exporting country governments. In the case of agricultural commodities, moreover, weather conditions can play an important role in the short run, while government policies (e.g., export and/or import taxes) can have significant impact in the longer run. Therefore, due to the existence of rather different processes in effect on the supply side, it is quite normal to observe different price movements in different commodity markets. 
Figure 7: Rolling-Sample System-Wide Connectedness

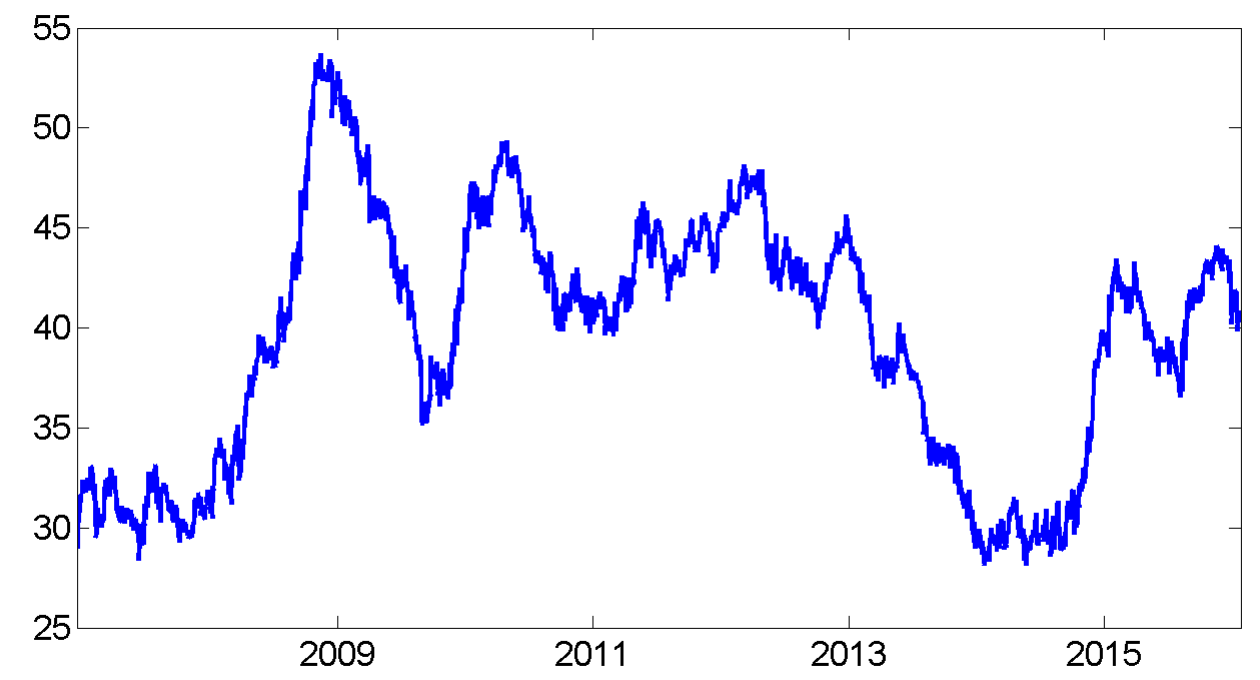

\subsection{System-Wide Connectedness}

We show total system-wide connectedness in Figure 7. It fluctuated between $28.3 \%$ and $53.8 \%$ over the sample period from the end of 2006 to the end of January 2016. Commodity return volatilities tend to generate lower connectedness than the global bank return volatilities, global stock market return volatilities, and bond yield volatilities. There are several reasons for this difference. Global bank return volatility shocks, in general, generate higher connectedness, because even though they are located in different countries, big global banks are subject to shocks to global banking as well as to international financial markets. Global stock market return volatility connectedness (and for that matter global bond market yield volatility connectedness) indices tend to be higher because return volatility shocks are likely to be transmitted within the same asset class across countries. When there is an idiosyncratic shock to one of the major stock markets or a shock common to a subset of stock markets it is likely to be transmitted to others.

Returning to dynamic system-wide volatility connectedness in commodity markets, we observe a spike in total connectedness around late 2008 and early 2009. The U.S. recession that started in the first half of 2008 triggered a global growth slowdown, which in turn prompted commodity prices to start falling in mid-2008, several months before the climax of the crisis was reached in the last quarter of 2008. The transformation of the U.S. financial crisis into a global one, and the resulting downward spiral in the world economy, accelerated 
the downward process of commodity prices that lasted until mid-2009.

As a result of these developments, system-wide connectedness increased from $32 \%$ at the end of February 2008 to close to $40 \%$ by the end of May 2008. After a brief respite, system-wide connectedness started to increase again, and following Lehman's bankruptcy it increased at a much faster pace from around $47 \%$ to $53.8 \%$ by mid-November.

Once it became apparent that global financial crisis would not lead to a complete meltdown of the financial system, commodity prices gradually turned upwards in early 2009, which in turn led the system-wide commodity connectedness turn downwards. The decline in connectedness was at first gradual, but it gained momentum in a couple of months time, dropping as low as $35 \%$ by the end of August 2009. The system-wide connectedness did not stay around 35\% for a long time. After a significant correction due to the global financial crisis, commodity prices started to recover from September 2009 onwards, as markets continued their upward journey, the volatility connectedness started to go up reaching as high as $48 \%$ by April 2010. During this upswing, there was not a widespread trend in the commodity return volatilities, but increased volatility in precious metals, especially in silver, caused the system-wide connectedness to increase slightly.

Commodity prices continued to increase until mid-2011, after which energy prices stayed more or less steady in the next three years or so, followed by a sharp drop in oil prices in the second half of 2014. In the meantime, agricultural commodities, as well as the industrial and precious metals followed a downward trend that lasted until the end of our sample. While the agricultural commodities' prices declined by an average of 35\%, that of precious and industrial metals respectively dropped by $45 \%$ and $52 \%$ over this period. Oil prices did not decline as fast as other major commodities because the impact of China on oil demand was more limited than the case in other commodities, especially in industrial metals. Secondly, the geopolitical risks in some countries in the Middle East and North Africa as well as Ukraine, when combined with Saudi Arabia's policy of adjusting its supplies to keep oil price high, together played a role in oil prices fluctuating in a band of $\$ 80-\$ 105$ per barrel for more than three years.

System-wide commodity volatility connectedness reflects the developments over the period. From the mid-2010 to early 2013 the system-wide connectedness fluctuated in the narrow band of 40\%-45\%. System-wde connectedness followed a short-lived upward trend early 2011 to early 2012, during which it reached as high as 48\%. This increase was mostly due to the worries about the political upheavals in the Middle East and North Africa. In particular, the worries about the Suez Canal due to the civil conflict in Egypt and the sharp 
cut in Libya's oil production due to the civil war in the country fed into the oil price volatility which in turn contributed to the system-wide connectedness in commodity markets. After the overthrow of Qaddafi regime in Libya 2011, the political crisis in Egypt was resolved with a coup d'etat in mid-July 2013. Following the turn of events in Egypt, volatility in oil prices subsided and the system-wide connectedness started to decline from around $37 \%$ in mid-July 2013 to $28.5 \%$ within six months.

After fluctuating around $30 \%$ for several months, system-wide connectedness started to increase from its lows of $30 \%$ in July 2014 to reach $43 \%$ by the early 2015 . The latest upward move in system-wide connectedness was due to worries about the civil war in Ukraine and whether it would lead to the temporary suspension of oil supplies from the Russian Federation to the world market.

At the same time, military actions of Russian-backed separatists increased confrontation between Russia, on the one side, and the U.S. and the EU, on the other side. It is speculated that as the tensions between the two sides increased, Saudi Arabia decided to change its policy of playing the marginal supplier which aims to keep oil prices high. With this policy change Saudi Arabia wanted to push high cost shale frackers out of business. Thanks to high global oil prices shale frackers were able to profitably increase global supply of oil, which threatened the dominant position of OPEC and in particular, Saudi Arabia, in the long-run. Secondly, Saudi Arabia helped the U.S. to increase pressure on the Russian government, which had become increasingly belligerent not only in Ukraine but in other civil unrests in parts of the world. As a result, the oil price was almost halved from around $\$ 100$ at the end of July 2014 to around $\$ 50$ by the end of the year.

After staying above $40 \%$ for several months, system-wide connectedness dropped to $37 \%$ in the summer of 2015, as the oil price ended its downward spiral and settled around $\$ 50$ per barrel. However, news about China's financial market troubles in August 2015 increased tensions and system-wide connectedness not only in commodity markets but in all financial markets. As a result, system-wide connectedness increased by more than five percentage points within a month and later reached $44 \%$ by the end of October 2015.

\subsection{Total Directional Connectedness}

In this section we analyze the dynamics of directional connectedness of individual commodities as well as commodity groups, based on net total directional connectedness graphs ( "to" - "from") in Figure 8.

As our discussion of the dynamic system-wide connectedness in the previous section 
Figure 8: Rolling-Sample Net Total Directional Connectedness
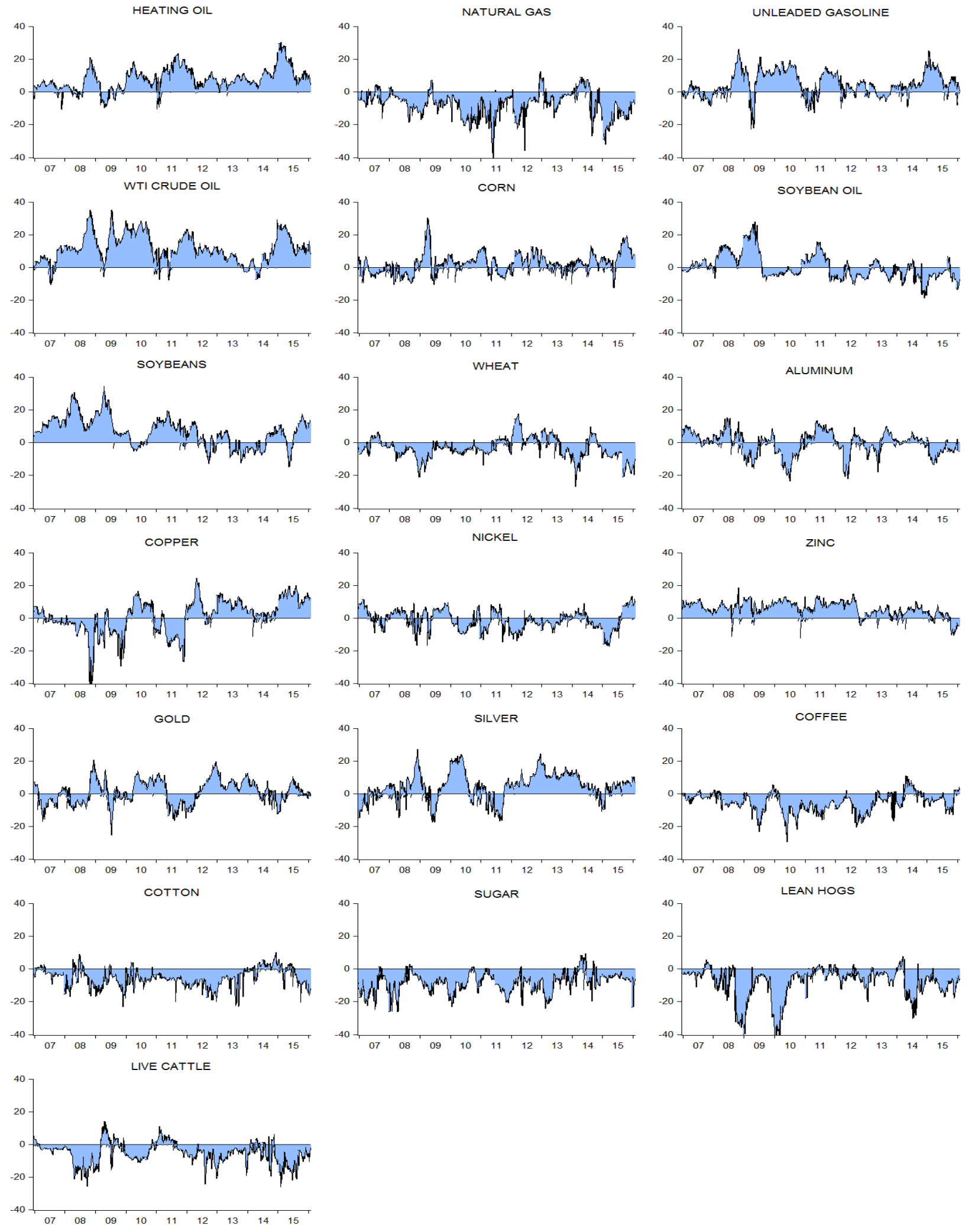
showed, and as Figure 8 confirms, oil played quite an important role in the commodity market connectedness. Its net connectedness is higher than all other commodities for an overwhelming majority of the rolling sub-sample windows considered. Both in earlier and later parts of the period, net connectedness of oil reached as high as 30-35\% range. The only sub-periods during which the net connectedness of crude oil was lower are the first half of 2007, and the period from the second half of 2013 to July 2014.

Starting in the first quarter of 2008, the crude oil price skyrocketed from around $\$ 60$ in February 2007 to reach $\$ 141$ per barrel by the first week of July 2008. After that moment, however, the oil price started to come down as the worries about U.S. economic performance intensified along with the signs of slowdown in many countries. As the downturn started in the oil price, oil return volatility increased substantially. Along with the rising oil return volatility, system-wide volatility connectedness increased from around 40\% in early July 2008 to $53 \%$ by the end of October 2008. Over the same period net connectedness of WTI crude oil increased from $10 \%$ to $35 \%$, the highest net connectedness level generated by a commodity for all rolling subsample windows considered (see Figure 8).

By the end of October 2008, the crude oil price dropped to $\$ 60$ per barrel. However, the downward spiral in the price of oil continued until the third week of December, with a minimum price of $\$ 31$ per barrel. As the oil price lost its downward momentum, its net connectedness oil dropped to around $10 \%$ by the end of 2008 . Once the oil price recovers to reach closer to $\$ 60$ per barrel, we observe that net volatility connectedness (hence volatility) of oil returns started to increase significantly and reached to $35 \%$ by mid-July 2009 .

Heating oil, soybeans and zinc are the three commodities that followed crude oil in generating very high levels of net connectedness to other commodities over all subsamples considered. Heating oil is also in the energy commodities group. Its net connectedness to others follows a trajectory which resembles to that of crude oil.

Soybeans have high net connectedness, not because they are an important consumption item for households around the world, but rather because they are used in the biofuel production. Soybeans' net connectedness reached as high as $28 \%$ in March 2008 and last quarter of 2008 and first half of 2009. Unlike crude oil, soybeans' net connectedness increased in January 2008 (exactly around the FOMC's emergency conference-call meeting on January 22) and at the end of February and beginning of March 2008. During this period, crude oil prices were still on an upward move with a net connectedness of only around 10\%. A similar asymmetric move between the net connectedness of crude oil and soybeans occurred in the first half of 2009. While crude oil's net connectedness declined from its peak at the 
end of October 2008 to a low of $-6 \%$ in the first week of April 2009, during this period the net connectedness of soybeans increased to reach $28 \%$ level.

Zinc is actually the only commodity that generated net positive connectedness to others throughout the period from 2006 to 2016. Throughout the period, zinc had small but positive (between 5 to 10\%) net connectedness from the beginning of the sample to the end of 2012. Its net connectedness declined significantly since late 2012 to less than $5 \%$, yet continued to stay on the positive side.

As for energy commodities, unleaded gasoline is the third in terms of generating net connectedness to other commodities. Again its net connectedness followed quiet a similar behavior over time to that of crude oil. The only energy commodity that is a net recipient of connectedness from others is natural gas. Natural gas is the energy market with the weakest link to the economic news flow, even when accounting for periods of recession. Reflecting this fact, its connectedness to others and from others are much lower than those of other energy commodities. As such its return volatility is likely to be affected by the return volatilities of other energy commodities. That is why its net connectedness was negative for an overwhelming majority of rolling sample windows, as shown in Figure 8.

We also need to focus on the net connectedness of copper. While its net connectedness was negative during the U.S. and global financial crisis in 2007 through 2009 and during the 2011 European debt crisis, copper has generated positive net connectedness since early 2012. Copper prices declined by more than $50 \%$ since the end of 2010 , from a high of $\$ 9,800$ per ton to a low of $\$ 4,700$ per ton at the end of 2015 . The decline in the price of copper and its increasing contribution to system-wide connectedness are closely related to the Chinese slowdown in recent years. Other industrial metals, such as zinc, nickel, and aluminum also experienced significant price drops over the period, but none of them had net connectedness as high as copper. We have already covered zinc above. The other two industrial metals, aluminum and nickel, displayed both positive and negative episodes. When considered all together industrial metals, industrial metals generated positive net connectedness to other commodity groups (ranging from 5 to 20\%) for almost all rolling window samples.

Among the precious metals, silver has higher net connectedness than gold for most of the period covered. During the global financial crisis, in the second half of 2009 and first half of 2010, and since the end of 2011, silver's net connectedness is much higher (sometimes as high as 20\%) than that of gold (see Figure 8).

Soft commodities (coffee, cotton and sugar) and livestock (lean hogs and live cattle) all have negative connectedness for almost all rolling sample windows, indicating that their 
prices on average are influenced by other commodities and/or commodity groups (see Figure 8).

\section{Conclusion}

We have estimated and examined the network graph for a set of major commodity subindex volatilities. The results reveal clear clustering of commodities into groups that match traditional industry groupings, but with some notable differences. The energy sector is most important in terms of sending shocks to others, and energy, industrial metals, and precious metals are themselves tightly connected.

\section{Appendices}

\section{A Verification of Key Properties of Realized Volatility}

Results for other markets like equities (Andersen et al. (2001a)) and foreign exchange (Andersen et al. (2001b)) indicate that daily realized volatilities are (1) generally distributed asymmetrically, with a right skew, but approximately Gaussian after taking natural logarithms, and (2) very strongly serially correlated. The economics of commodity markets are quite different from those of foreign exchange or equities, however, so here we provide an examination of fundamental distributional and dynamic properties of commodity volatilities.

Let us start with distributional aspects. As obviously revealed in the Gaussian Q-Q plots of Figure 9, the distribution of realized commodity volatility is strongly skewed right. This is not surprising, because volatilities are bounded below by zero and experience occasional large bursts. The real issue is whether $\log$ commodity volatilities are approximately Gaussian, as with foreign exchange and equities. As shown in the Gaussian Q-Q plots for log returns in Figure 10, the answer is mostly yes. ${ }^{13}$

Finally, we consider dynamics. In Figure 11 we show volatility autocorrelations. They decay, which is consistent with covariance stationarity, but they decay very slowly, indicating highly persistent, if nevertheless mean-reverting, dynamics.

\footnotetext{
${ }^{13}$ The only exceptions to approximate log-normality are three industrial metals (aluminum, nickel, zinc), as clearly shown in the Gaussian Q-Q plots of Figure 10. All are traded on the London metals exchange (LME), and they are the only commodities in our data set traded on that exchange.
} 


\section{B Different Horizons (Various $h$, Fixed $p=3$ )}

It is of interest to explore connectedness at different horizons $h$. On the one hand, one might hope for results robust to horizon. On the other hand, upon further consideration, it is not obvious why the results should be robust, or whether such robustness is "desirable". This point is related to different notions of network centrality; one can assess 1-step through the adjacency matrix $A, 2$-step through $A^{2}$, and so on to $\infty$-step (eigenvalue centrality).

First consider static connectedness. In Figure 12, we show static (full-sample) $V A R(3)$ network connectedness graphs for six variance decomposition horizons: $h=2,10,20, \ldots, 50$ days. The different subgraphs are rotated to enhance multiple comparisons. The topology appears strongly robust to horizon. ${ }^{14}$

\section{Different Dynamics (Fixed $h=10$, Various $p$ )}

We already noted the very high persistence in commodity return volatilities, as is common across many assets and asset classes. Indeed there may even be long memory, as emphasized in Andersen et al. (2003). To allow for that possibility, we also explored a variety of higher-order approximating models, estimation of which is feasible despite profligate parameterizations, given the regularization achieved by the LASSO.

In Figure 13, we show static (full-sample) $h=10$ network connectedness graphs for six $V A R$ lag orders, $p=3,5,10,15,20,25$. The different subgraphs are rotated to enhance multiple comparisons. The topology appears strongly robust to lag order.

\footnotetext{
${ }^{14}$ The scaling, however, differs across the subgraphs; otherwise the small- $h$ graphs would be tiny and the large- $h$ graphs would be huge.
} 
Figure 9: Gaussian Q-Q Plots for Realized Volatilities
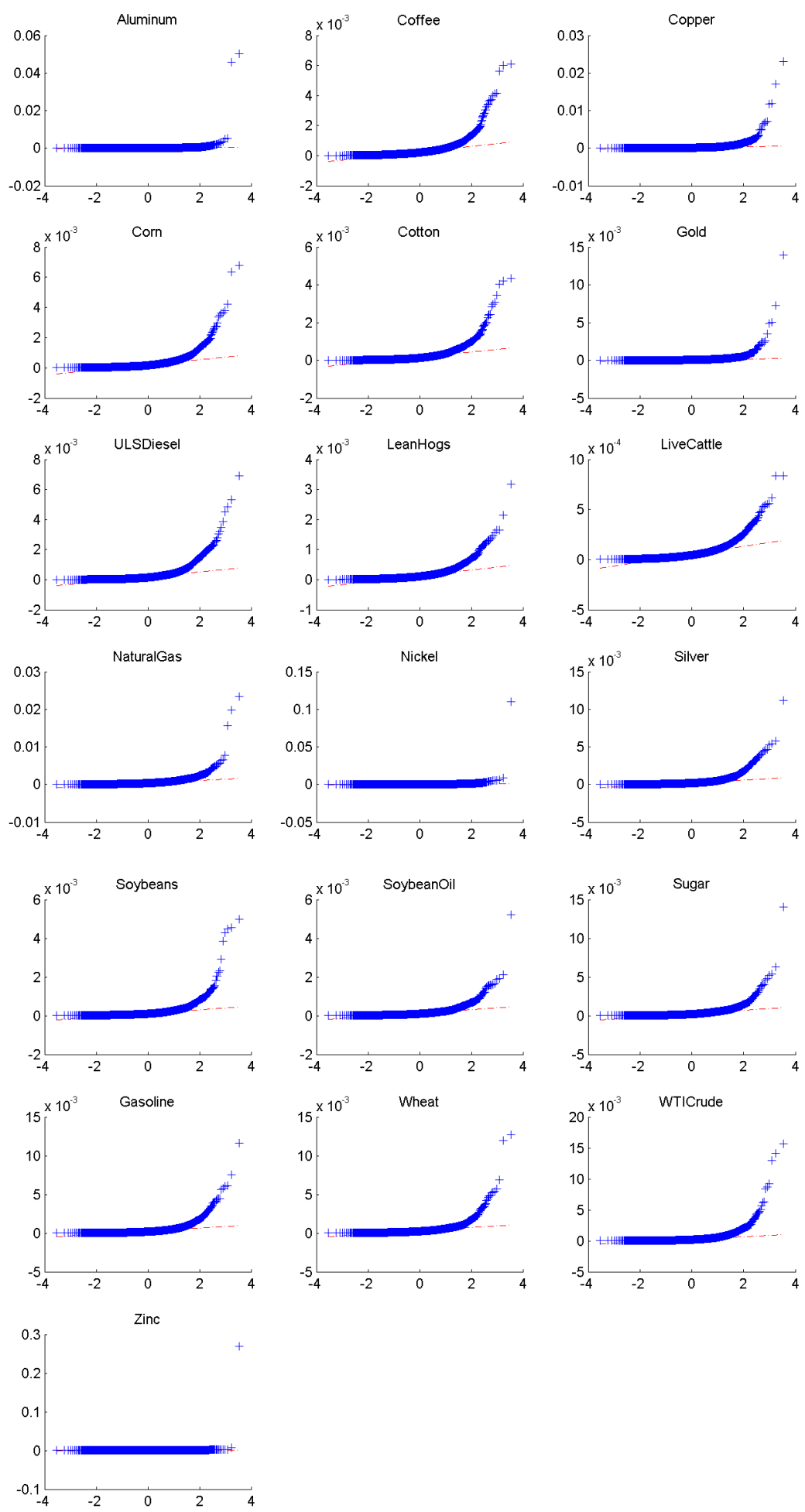
Figure 10: Gaussian Q-Q Plots for Log Realized Volatilities
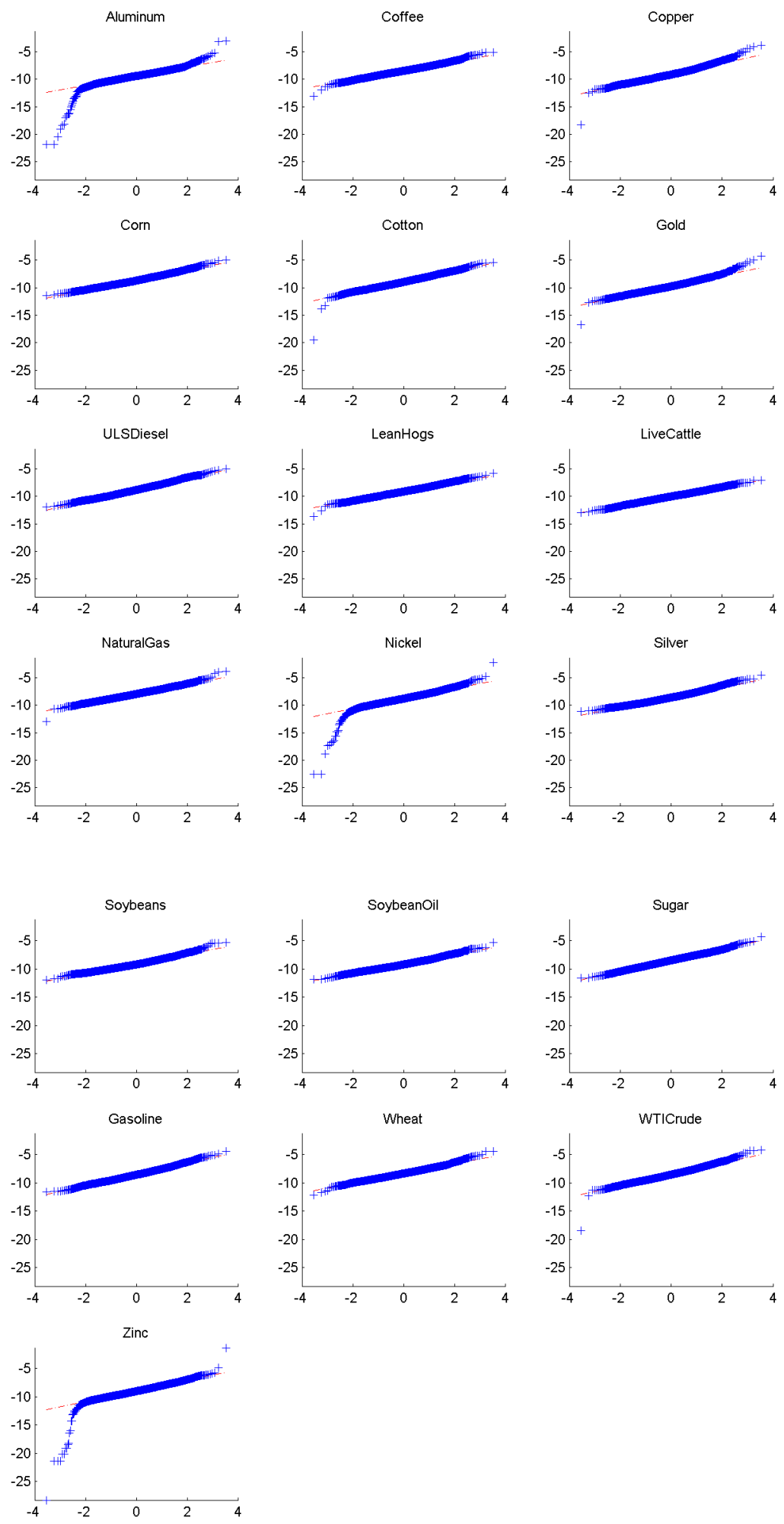
Figure 11: Sample Autocorrelation Functions of Log Realized Volatilities
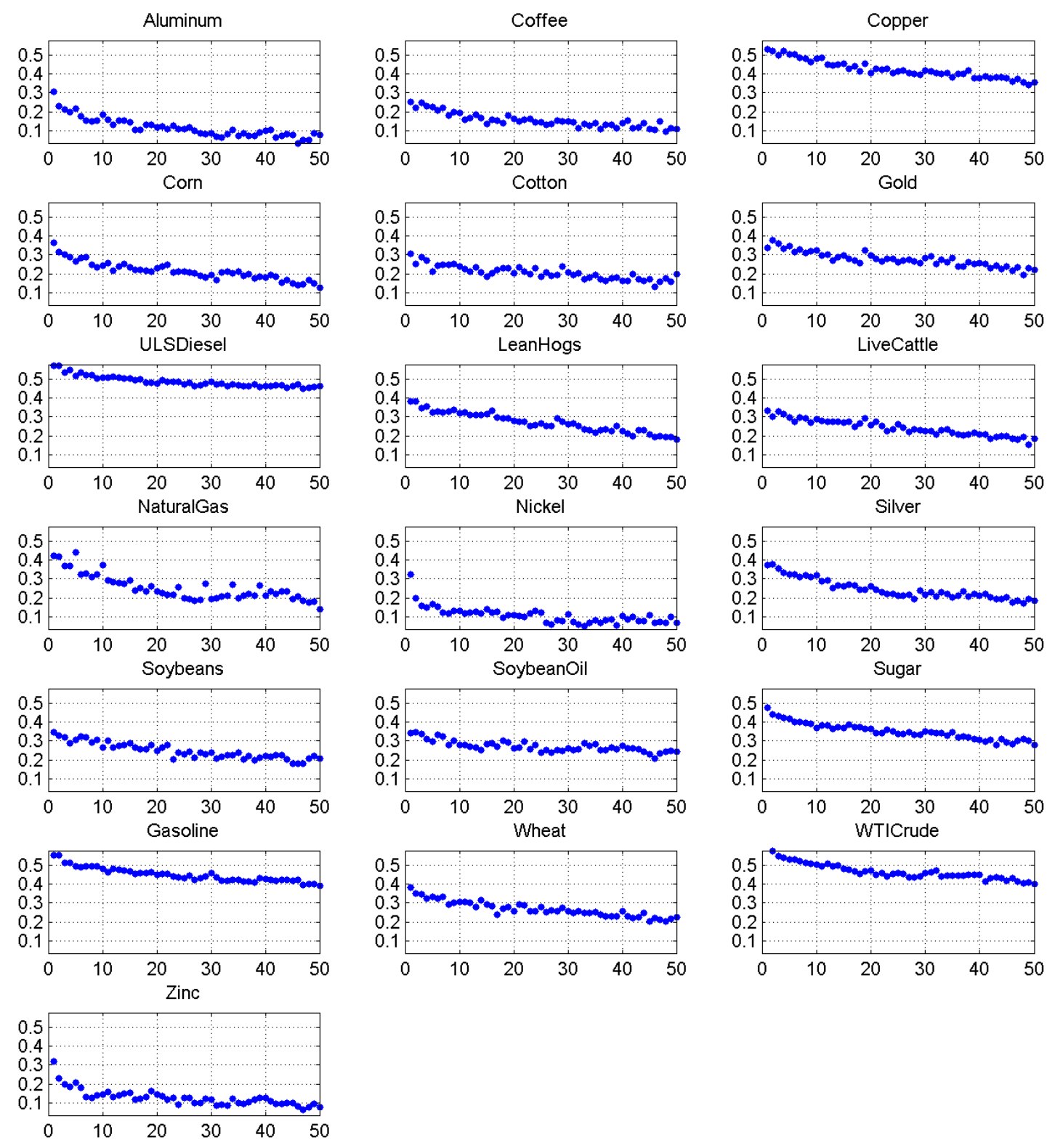
Figure 12: Full-Sample Connectedness, $V A R(3)$, Different Horizons
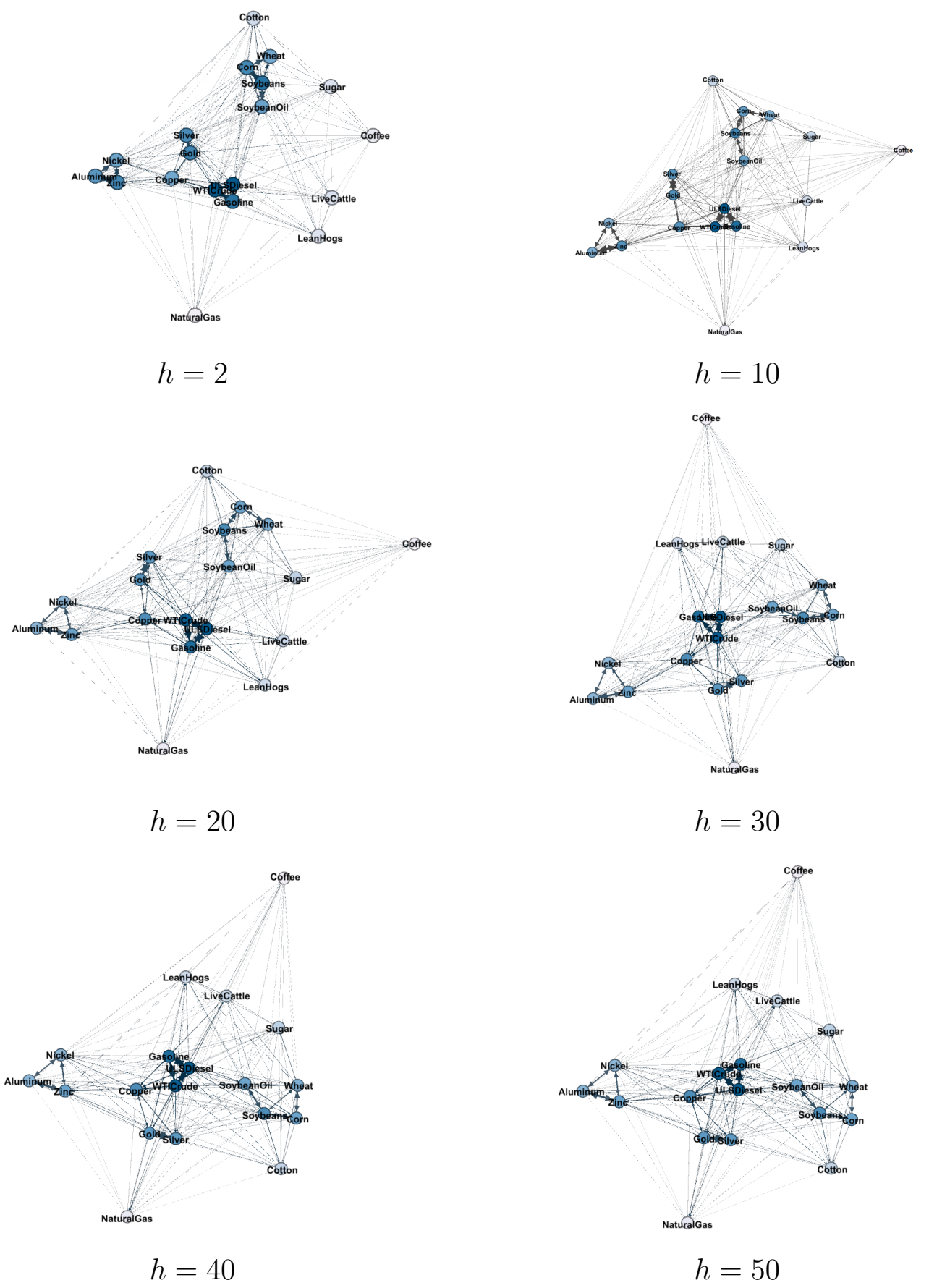
Figure 13: Full-Sample Connectedness, Different $V A R$ Orders, $h=10$
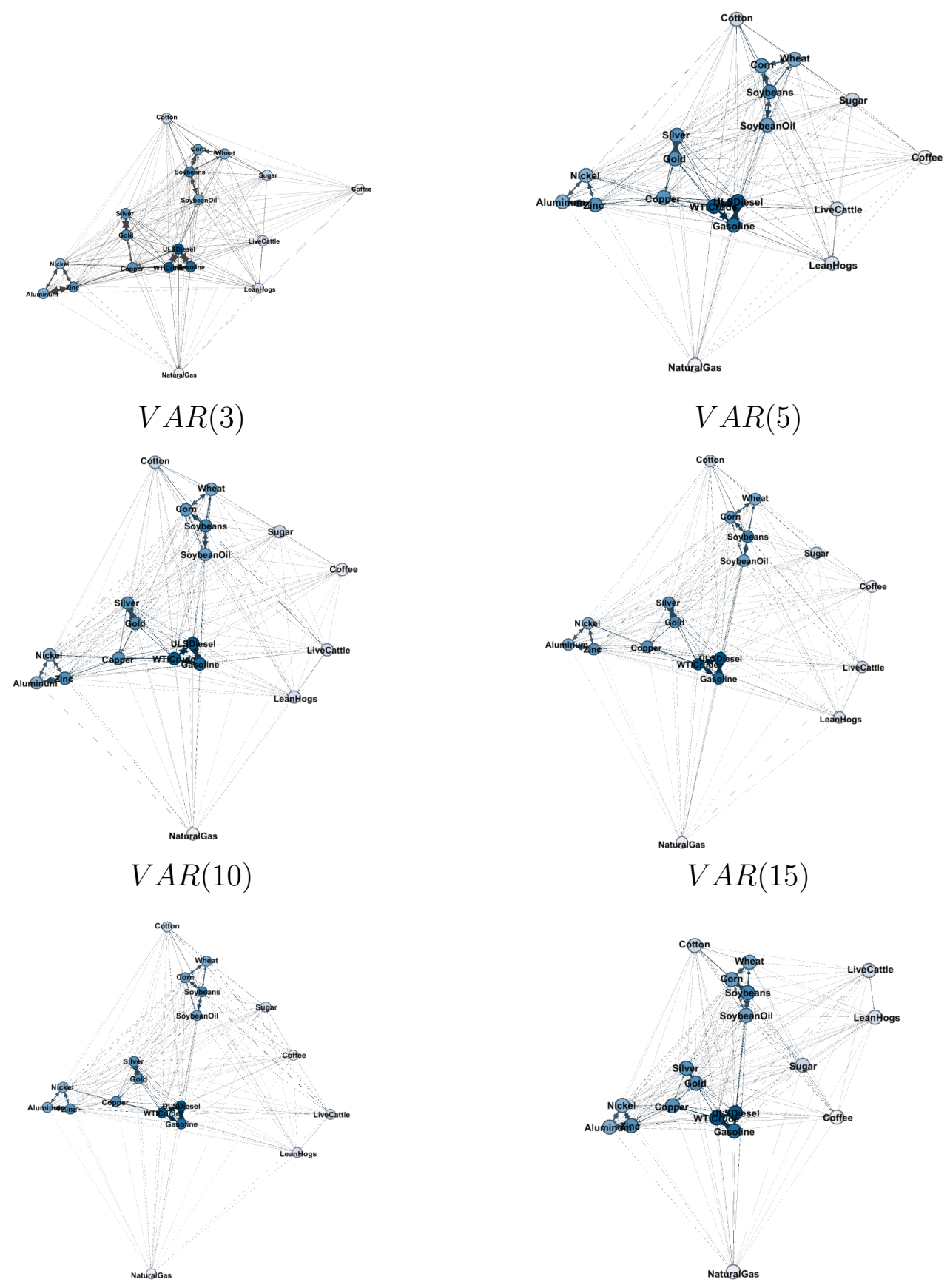

$V A R(20)$

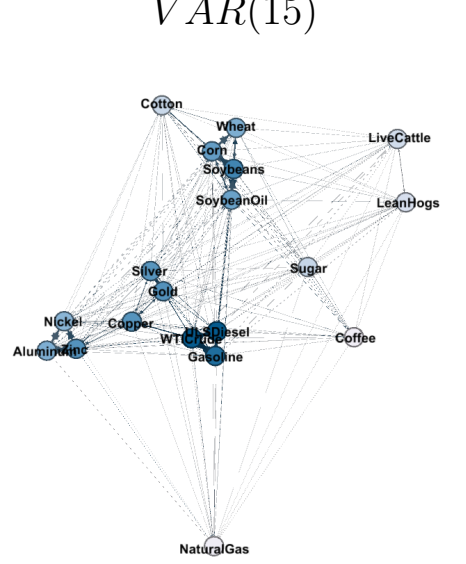

$V A R(25)$ 


\section{References}

Acharya, V.V., L. Pedersen, T. Philippon, and M. Richardson (2010), "Measuring Systemic Risk," Manuscript, New York University.

Adrian, T. and M. Brunnermeier (2016), "CoVaR," American Economic Review, 106, 17051741.

Alizadeh, S., M.W. Brandt, and F.X. Diebold (2002), "Range-Based Estimation of Stochastic Volatility Models," Journal of Finance, 57, 1047-1091.

Andersen, T.G., T. Bollerslev, F.X. Diebold, and H. Ebens (2001a), "The distribution of realized stock return volatility," Journal of Financial Economics, 61, 43-76.

Andersen, T.G., T. Bollerslev, F.X. Diebold, and P. Labys (2001b), "The distribution of realized exchange rate volatility," Journal of the American Statistical Association, 96, $42-55$.

Andersen, T.G., T. Bollerslev, F.X. Diebold, and P. Labys (2003), "Modeling and forecasting realized volatility," Econometrica, 71, 579-625.

Billio, M., M. Getmansky, A.W. Lo, and L. Pelizzon (2012), "Econometric Measures of Connectedness and Systemic Risk in the Finance and Insurance Sectors," Journal of Financial Economics, 104, 535-559.

Bloomberg (2016), "Index Methodology: The Bloomberg Commodity Index Family," https: //www.bbhub.io/indices/sites/2/2016/05/BCOM-Methodology-April-2016.pdf.

Bonaldi, P., A. Hortaçsu, and J. Kastl (2013), "An Empirical Analysis of Systemic Risk in the EURO-zone," Manuscript, University of Chicago.

Chevallier, J. and F. Ielpo (2013), The Economics of Commodity Markets, John Wiley.

Demirer, M., F.X. Diebold, L. Liu, and K. Yilmaz (2016), "Estimating Global Bank Network Connectedness," SSRN Working Paper 2631479, available at http://ssrn.com/ abstract $=2631479$.

Diebold, F.X. and K. Yilmaz (2009), "Measuring Financial Asset Return and Volatility Spillovers, with Application to Global Equity Markets," Economic Journal, 119, 158171. 
Diebold, F.X. and K. Yilmaz (2012), "Better to Give than to Receive: Predictive Measurement of Volatility Spillovers (with discussion)," International Journal of Forecasting, 28, 57-66.

Diebold, F.X. and K. Yilmaz (2014), "On the Network Topology of Variance Decompositions: Measuring the Connectedness of Financial Firms," Journal of Econometrics, 182, 119134.

Fernández, A., A. González, and D. Rodriguez (2015), "Sharing a Ride on the Commodities Roller Coaster: Common Factors in Business Cycles of Emerging Economies," Inter-American Development Bank Working Paper Series No. IDB-WP-640, available at http://www.iadb.org/en/research-and-data/publication-details, 3169.html? pub_id=IDB-WP-640.

Garman, M. B. and M. J. Klass (1980), "On the Estimation of Security Price Volatilities From Historical Data," Journal of Business, 53, 67-78.

Kara, G.I., M.H. Tian, and M. Yellen (2015), "Taxonomy of Studies on Interconnectedness," SSRN Working Paper 2704072, available at http://ssrn. com/abstract=2704072.

Kat, H.M. and R.C.A Oomen (2007a), "What Every Investor Should Know About Commodities, Part I," Journal of Investment Management, 5:1, 4-28.

Kat, H.M. and R.C.A Oomen (2007b), "What Every Investor Should Know About Commodities, Part II: Multivariate Return Analysis," Journal of Investment Management, 5:3, $16-40$.

Koop, G., M.H. Pesaran, and S.M. Potter (1996), "Impulse Response Analysis in Nonlinear Multivariate Models," Journal of Econometrics, 74, 119-147.

Pesaran, H.H. and Y. Shin (1998), "Generalized Impulse Response Analysis in Linear Multivariate Models," Economics Letters, 58, 17-29.

World Bank (July 2015), Commodity Market Outlook.

World Bank (October 2014), Commodity Market Outlook. 